\title{
Robotic-Assisted Gait Training Effect on Function and Gait Speed in Subacute and Chronic Stroke Population: A Systematic Review and Meta-Analysis of Randomized Controlled Trials
}

\author{
Jaya Shanker Tedla ${ }^{a}$ Snehil Dixit ${ }^{a}$ Kumar Gular ${ }^{a}$ Mohammed Abohashrh ${ }^{b}$ \\ a Department of Medical Rehabilitation Sciences, College of Applied Medical Sciences, King Khalid University, Abha, \\ Saudi Arabia; ${ }^{b}$ Department of Basic Medical Science, College of Applied Medical Sciences, King Khalid University, \\ Abha, Saudi Arabia
}

\section{Keywords}

Stroke $\cdot$ Robotic-assisted gait training $\cdot$ Gait speed

\begin{abstract}
Background: The review is intended to provide the effectiveness of robotic-assisted gait training (RAGT) for functional gait recovery in poststroke survivors through a systematic review and to provide evidence for gait speed improvements through the meta-analysis of randomized controlled trials (RCTs). Summary: In this systematic review, PubMed, Web of Science, Wiley Online Library, Science Direct, Science Robotics, Scopus, UpToDate, MEDLINE, Google Scholar, CINHAL, EMBASE, and EBSCO were reviewed to identify relevant RCTs. Articles included in the study were thoroughly examined by 2 independent reviewers. The included RCTs were having a PEDro score between 6 and 8 points. The initial database review yielded 1,371 studies and, following further screening; 9 studies finally were selected for systematic review and meta-analysis. Out of the 9 studies, 4 were on chronic stroke and 5 were on subacute stroke. The metaanalysis of gait speed showed an effect size value ranging between -0.91 and 0.64 , with the total effect size of all the studies being -0.12 . During subgroup analysis, the subacute
\end{abstract}

stroke total effect size was identified as -0.48 , and the chronic stroke total effect size was noted as 0.04 . Meta-analysis revealed no significant differences between RAGT and conventional gait training (CGT). Key Messages: Our systematic review revealed that the RAGT application demonstrated a better or similar effect to that of CGT in a poststroke population. A meta-analysis of gait speed involving all the studies identified here indicated no significant differences between RAGT and CGT. However, the subanalysis of chronic stroke survivors showed a slight positive effect of RAGT on gait speed.

C 2019 S. Karger AG, Basel

\section{Introduction}

The third major leading cause of death worldwide is stroke [1]. Stroke has been attributed to a variety of impairments depending on the area of involvement in the brain, giving rise to the onset of temporary or permanent activity limitations in most stroke survivors [2]. Due to the evolving lifestyle and stress factors, it is believed that females more typically suffer a stroke before 30 years of age, while males suffer stroke usually after 30 years of age 
[2]. These findings show a clear shift in the paradigm of stroke. If the current scenario remains unconstrained, it is believed that there will be as many as 70 million stroke survivors around the world by 2030 [3].

There is a need for rehabilitative interventions that can address the problems of stroke, thereby decreasing the number of impairments among stroke survivors. Robotics is one emerging technology that is able to be effectively deployed for use by the affected population so as to improve their physical activity and social participation [3]. There is a growing thought that the application of robotics leads to early walking recovery among the stroke population [3-5].

Sensory-motor impairment among stroke survivors is quite common, impacting almost $60 \%$ of the population [6]. In particular, sensory-motor impairments majorly affecting the lower limbs may lead to a reduction in stance time and/or abnormal gait parameters [6]. It is estimated that lower limb problems that occur poststroke affect as many as $65 \%$ of stroke survivors [7]. The usual concept for early intervention is conservative physical therapy and this in combination with robotic assistance is the most accepted therapy in the current clinical scenario. The use of robotics in this manner can assist the therapist in improving the activity of paretic or paralyzed lower limbs [8].

There are various forms of robotic devices available commercially at this time. These options have been categorized according to the motion they apply. For example, "exoskeletons" move joints, such as the hips, knees, and ankles, in coordination with phases of gait, whereas "end-effector robots" move only the feet, which are often placed on a support (footplate) [3]. Roboticassisted gait training (RAGT) is either applied in combination with conservative physiotherapy or individually. Studies have also stated that treatment involving RAGT in combination with the conventional form of physical therapy is more advantageous in terms of increased training volume and more reproducible symmetrical gait patterns that can be performed with minimal load on the therapist [1]. Still, there is growing consensus that the conventional form of physical therapy should not be replaced entirely by RAGT [3], as the applied devices are merely such in hands of a physical therapist and therapists themselves ultimately provide unique benefits to the treatment protocols in the stroke population [3].

During the rehabilitation of poststroke survivors, regaining the walking capacity is cardinal; walking speed is one objective, sensitive, and consistent gait parameter. A good walking speed constitutes a crucial factor for social participation [9-11].

Hence, there still appears to be a dearth in the literature regarding the role of interventions with RAGT in combination with conventional physical therapy (CPT) among stroke survivors for functional gait recovery. The present objective of the study is to generate evidence for the effectiveness of RAGT on functional recovery and gait speed by conducting a systematic review and meta-analysis of randomized controlled trials (RCTs).

\section{Methodology}

\section{Search Methods}

Two independent reviewers screened related studies after following a search strategy based on the established inclusion criteria. The reviewers extracted the full texts of all relevant RCTs and their respective levels of methodological quality were assessed using the PEDro scale. The studies, which all scored 4 or more points on the PEDro scale, were included for the review process.

\section{Search Strategy}

For this study, we considered research from the following databases: PubMed, the Web of Science, the Wiley Online Library, ScienceDirect, Science Robotics, Scopus, UpToDate, MEDLINE, Google Scholar, CINHAL, EMBASE, and EBSCO. Studies published between 2000 and 2018 were included in this review. Keywords used to extract studies were "RAGT," "stroke," "subacute," "chronic stroke," "cerebrovascular accidents," "hemiparesis," "hemiplegia," "functional recovery," and "gait parameters." Reviewers also identified additional studies from the reference lists of the selected research papers. Only studies published in the English language were eligible for inclusion.

Types of Studies

In this review, we included only RCTs that considered the effects of RAGT in subacute and chronic stroke survivors.

\section{Selection Criteria}

RCTs conducted on subacute/chronic stroke survivors who were older than 18 years of age and which examined the use of RAGT alone or RAGT in combination with CPT or versus CPT in a control group were included. Moreover, the studies, which used static exoskeleton device training and gait parameters as one of the outcome measures, were also involved in the review process.

Studies conducted on acute stroke survivors; nonrandomized trials; those with the experimental group using end-effector robotics or dynamic exoskeleton devices; and robotic studies on upper limb function were excluded from the review process.

\section{Types of Outcome Measures}

The primary outcome measure for the present review was gait velocity/walking speed. Secondary outcomes measures were related to muscle tone, lower limb muscle power, gait, functional balance, activity specific balance confidence, and quality of life. 
Fig. 1. Flow chart for the screening and inclusion of studies for systematic review and meta-analysis. RCTs, randomized controlled trials.

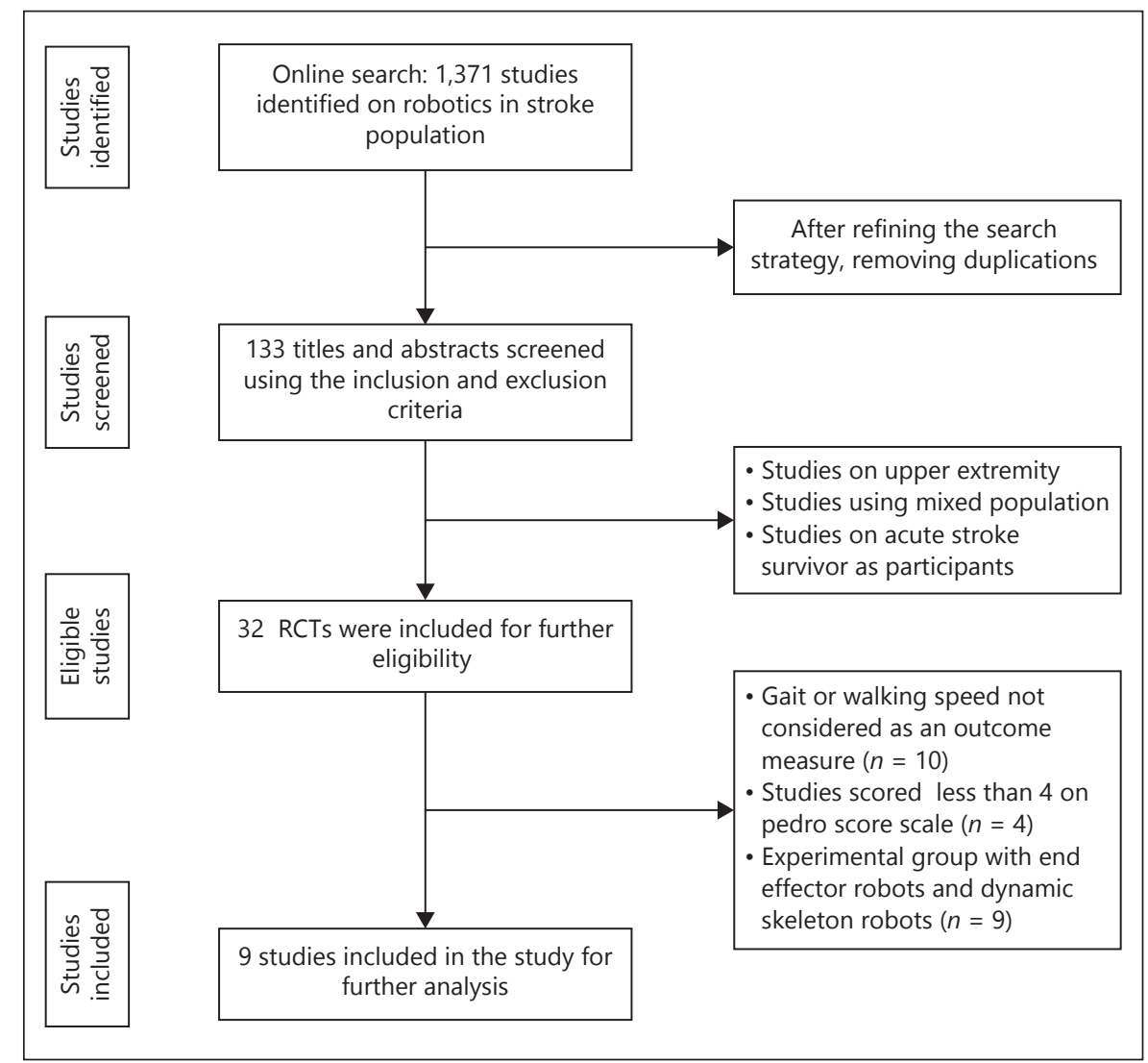

\section{Duration of the Intervention}

In this review, the duration of the intervention for the included studies was considered in accordance with the American Heart Association guidelines for physical activity poststroke [12].

\section{Methodological Quality}

Two independent reviewers evaluated the studies, with an opinion from a third reviewer considered in the event of any disagreement. These reviewers were not blinded to the authors, institutions, or journals during the review process. The quality of the RCTs was designated based on the PEDro scoring system as excellent ( $9-10$ points), good ( $6-8$ points), fair $(4-5$ points), or poor $(<4$ points). Studies having a PEDro score of $\geq 6$ points were designated as being of Level 1 evidence and were considered as high-quality evidence. Moreover, these studies were subdivided into the la (strong) and $1 \mathrm{~b}$ (moderate) levels of evidence as established by Snider et al. [13].

\section{Assessment Criteria for Performing a Meta-Analysis}

We used the correlation coefficient ( $r$ value) as a measure of effect size. The effect size was calculated based on the before and after mean and SD values of the experimental and control groups. The differences between the before and after mean and SD values for the aforementioned groups, respectively, were averaged and stabilized mean differences were established. Based on the stabilized mean differences and the number of participants involved in a certain study, the SE was calculated. Using this SE, a stabilized mean difference value, 95\% CI, and $r$ value were calculated. Pooled effect sizes were classified as trivial (0-0.2), small (0.2-0.5), moderate (0.5-0.8), or large $(>0.8)$.

\section{Results}

In total, 1,371 studies were identified using the abovementioned search strategy, out of which 133 studies were limited to RAGT in the stroke population. After a cautious screening of these 133 studies based on the selection criteria, only 32 RCTs were selected. Among the 32 studies, 10 studies did not consider gait speed as the outcome measure; 4 studies scored $<4$ points on the PEDro scale; and, in 9 studies, the experimental group used end-effector and/or dynamic skeleton robots. Finally, only 9 randomized control trials [14-22] were included for systematic review and meta-analysis. Figure 1 summarizes in detail the flow of the studies that were ultimately included in the review process. The PEDro scores of all the included studies are listed in Table 1. The included RCTs have PEDro scores that range between 6 and 8 points. 
Table 1. Methodological quality assessment of RCT's using PEDro scoring system

\begin{tabular}{|c|c|c|c|c|c|c|c|c|c|c|c|c|}
\hline Author/references & 1 & 2 & 3 & 4 & 5 & 6 & 7 & 8 & 9 & 10 & 11 & $\begin{array}{l}\text { PEDro } \\
\text { score }(10)\end{array}$ \\
\hline Hornby et al. [14] & $\sqrt{ }$ & $\checkmark$ & $\checkmark$ & $\checkmark$ & $x$ & $x$ & $x$ & $\checkmark$ & $\checkmark$ & $\checkmark$ & $\checkmark$ & 7 \\
\hline Husemann et al. [16] & $\checkmark$ & $\checkmark$ & $\checkmark$ & $\checkmark$ & $x$ & $x$ & $\checkmark$ & $\checkmark$ & $\checkmark$ & $\checkmark$ & $\checkmark$ & 8 \\
\hline Hidler et al. [17] & $\checkmark$ & $\checkmark$ & $x$ & $\checkmark$ & $x$ & $x$ & $\times$ & $\checkmark$ & $\checkmark$ & $\checkmark$ & $\checkmark$ & 6 \\
\hline Taveggia et al. [18] & $\checkmark$ & $\checkmark$ & $x$ & $\checkmark$ & $x$ & $x$ & $\checkmark$ & $\checkmark$ & $\checkmark$ & $\checkmark$ & $\checkmark$ & 7 \\
\hline Morone et al. [20] & $\checkmark$ & $\checkmark$ & $x$ & $\checkmark$ & $x$ & $x$ & $\checkmark$ & $\checkmark$ & $\checkmark$ & $\checkmark$ & $\checkmark$ & 7 \\
\hline Kelley et al. [21] & $\checkmark$ & $\checkmark$ & $\checkmark$ & $\checkmark$ & $x$ & $x$ & $\checkmark$ & $\checkmark$ & $\checkmark$ & $\checkmark$ & $\checkmark$ & 8 \\
\hline Bang and Shin [22] & $\checkmark$ & $\checkmark$ & $\checkmark$ & $\checkmark$ & $x$ & $x$ & $\checkmark$ & $\checkmark$ & $\checkmark$ & $\checkmark$ & $\checkmark$ & 8 \\
\hline
\end{tabular}

RCTs, randomized controlled trials.

Among the 9 RCTs, 4 studies were done on chronic stroke and 5 studies were performed on subacute stroke survivors. In the above-included studies, RAGT with or without CPT in the experimental group was compared with Therapist-Assisted Gait Training [14, 21], manual Body Weight Supported Treadmill Training [15], Conventional Gait Training [16, 20], walking activities [18], and over-ground gait training [19], with or without CPT in the control group.

Among the 9 included studies, 4 studies included a CPT intervention along with RAGT. Conversely, the rest of the 5 studies with a RAGT group did not apply any CPT.

Lokomat ${ }^{\circledR}$ (Hocoma AG, Volketswil, Switzerland) was the most commonly used machine in 7 studies. The Lokomat ${ }^{\circledR}$ gait assistant robot [19] and gait trainer robot [20] machines were generally used for gait training in the RAGT group. The ranges of treatment times and frequencies were $30 \mathrm{~min}$ to $1 \mathrm{~h} /$ session, 3-4 times/per week, lasting 4-10 weeks, and yielding an overall 12-25 sessions. Gait speed was the primary outcome measure in all RCTs. The other outcome measures used were the 6-min walking test, 10-min walking test, the 36-Item Short Form Health Survey, the Tinetti Scale, the Functional Ambulatory Capacity Scale, the Functional Independence Measure, the FugelMeyer Lower Extremity Assessment, the Rivermead Mobility Index, muscle torque, the Barthel Index, the Stroke Impact Scale, the Berg Balance Scale, and the Frenchay Activities Index. The particulars of all the primary and secondary outcome measures are presented in Table 2.

While considering gait speed, out of the 9 included RCTs, in 2 studies, the experimental group showed significant improvement in the outcome measures as compared with the control group $[20,22]$. In the 6 studies with an experimental group versus control group setup, there were no significant differences in the outcomes [14-16, 19-21]. In one study [17], the control group showed superior effects in comparison with the experimental group. The details of improvements are presented in Table 3.

A meta-analysis of the gait speed was performed for all 9 RCTs. Furthermore, subgroup analyses were completed for the subacute and chronic stroke RCTs separately. The effect size values ranged from -0.91 to 0.64 , and the total effect size of all 9 studies was trivial at -0.12 . The subgroup analysis findings were not significantly different from the total effect size values: the subacute stroke total effect size was small at -0.48 and the chronic stroke total effect size was similarly trivial at 0.04 . Out of all these meta-analyses, only chronic stroke subjects experienced a slightly positive effect in the robotic group versus in the control group. The details of the meta-analyses are provided in Figure 2 and Table 4.

\section{Discussion}

The current review focused on the effects of RAGT in the stroke population. This is a unique review that considered the consequences of RAGT on gait parameters, function, and patient quality of life. Among the gait parameters, we considered gait speed in a meta-analysis.

Of the 9 studies included herein, only 2 studies showed superior effects of RAGT over those of the control group. The superior effects of RAGT can be attributed to the following reasons: more steps were practiced per session $[20$, 22] symmetrical gait can be facilitated [22], and paretic leg step length symmetry is better [15]. Moreover, in the RAGT group, faster training speeds are possible along with an increased duration of training, which can aid with 
Table 2. General characteristics of the studies included in the systematic review

\begin{tabular}{|c|c|c|c|c|c|c|c|c|c|}
\hline Author & Subjects & Treatment & $\begin{array}{l}\text { Experimental } \\
\text { group } \\
\text { intervention }\end{array}$ & $\begin{array}{l}\text { Control group } \\
\text { intervention }\end{array}$ & RAGT by & $\begin{array}{l}\text { Treatment } \\
\text { parameters }\end{array}$ & $\begin{array}{l}\text { Primary } \\
\text { outcomes }\end{array}$ & $\begin{array}{l}\text { Secondary } \\
\text { outcome's }\end{array}$ & Conclusions \\
\hline $\begin{array}{l}\text { Hornby et al. } \\
{[14]}\end{array}$ & $\begin{array}{l}\text { Chronic } \\
\text { stroke }\end{array}$ & $\begin{array}{l}\text { Therapist } \\
\text { versus robotic- } \\
\text { assisted LT }\end{array}$ & RAGT & TAGT & LOKOMAT & $\begin{array}{l}30 \mathrm{~min} / \text { day } \\
\text { Number of } \\
\text { weeks not } \\
\text { specified } \\
12 \text { sessions }\end{array}$ & Gait speed & $\begin{array}{l}6 \text { MWT, } \\
\text { mEFAP, BBS, } \\
\text { FAI, SF36 }\end{array}$ & $\begin{array}{l}\text { Therapist assisted } \\
\text { LT is superior to } \\
\text { robot assisted LT }\end{array}$ \\
\hline $\begin{array}{l}\text { Westlake and } \\
\text { Patten [15] }\end{array}$ & $\begin{array}{l}\text { Chronic } \\
\text { stroke }\end{array}$ & $\begin{array}{l}\text { Robotic versus } \\
\text { manual assisted } \\
\text { treadmill } \\
\text { training }\end{array}$ & $\begin{array}{l}\text { Lokomat- } \\
\text { RAGT }\end{array}$ & $\begin{array}{l}\text { Manual } \\
\text { BWSTT }\end{array}$ & LOKOMAT & $\begin{array}{l}30 \mathrm{~min} / \text { day } \\
3 \text { times/week } \\
4 \text { weeks } \\
12 \text { sessions }\end{array}$ & $\begin{array}{l}\text { Self-selected } \\
\text { walking speed, } \\
\text { paretic step } \\
\text { length ratio }\end{array}$ & $\begin{array}{l}\text { Fast walking } \\
\text { speed, } 6 \text { MWT, } \\
\text { fugl-meyer (LE), } \\
\text { BBS, SPPB, } \\
\text { LLFDI }\end{array}$ & $\begin{array}{l}\text { Walking speed } \\
\text { increased in both the } \\
\text { groups but there is no } \\
\text { significant difference } \\
\text { between both the } \\
\text { groups }\end{array}$ \\
\hline $\begin{array}{l}\text { Husemann et al. } \\
{[16]}\end{array}$ & $\begin{array}{l}\text { Subacute } \\
\text { stroke }\end{array}$ & $\begin{array}{l}\text { RAGT versus } \\
\text { CPT }\end{array}$ & $\begin{array}{l}\text { LOKOMAT + } \\
\text { CPT }\end{array}$ & $\mathrm{CGT}+\mathrm{CPT}$ & LOKOMAT & $\begin{array}{l}1 \mathrm{~h} / \text { day } \\
5 \text { times/week } \\
4 \text { weeks } \\
20 \text { sessions }\end{array}$ & $\begin{array}{l}\text { MGH, FAC } \\
10 \mathrm{MWT}\end{array}$ & $\begin{array}{l}\text { Gait parameters, } \\
\text { barthel index, } \\
\text { muscle tone }\end{array}$ & $\begin{array}{l}\text { Both groups } \\
\text { improved. } \\
\text { LOCOMAT better } \\
\text { than CPT to improve } \\
\text { gait but not function }\end{array}$ \\
\hline $\begin{array}{l}\text { Hidler et al. } \\
\text { [17] }\end{array}$ & $\begin{array}{l}\text { Subacute } \\
\text { stroke }\end{array}$ & $\begin{array}{l}\text { RAGT versus } \\
\text { CGT }\end{array}$ & RAGT & CGT & LOKOMAT & $\begin{array}{l}45 \mathrm{~min} / \text { day } \\
3 \text { times/week } \\
8-10 \text { weeks } \\
24 \text { sessions }\end{array}$ & $\begin{array}{l}\text { Self-selected } \\
\text { walking Speed } \\
6 \mathrm{MWT}\end{array}$ & $\begin{array}{l}\text { BBS, FAC, NIH } \\
\text { stroke scale, } \\
\text { MAS, RMI, } \\
\text { FAI, rand } \\
\text { 36-item health } \\
\text { survey }\end{array}$ & $\begin{array}{l}\text { CGT more effective } \\
\text { than RAGT }\end{array}$ \\
\hline $\begin{array}{l}\text { Taveggia et al. } \\
{[18]}\end{array}$ & $\begin{array}{l}\text { Subacute } \\
\text { stroke }\end{array}$ & $\begin{array}{l}\text { Robotic versus } \\
\text { usual gait } \\
\text { training }\end{array}$ & $\begin{array}{l}\text { Lokomat- } \\
\text { RAGT + } \\
\text { Conventional } \\
\text { PT (bobath } \\
\text { concept) }\end{array}$ & $\begin{array}{l}\text { Walking } \\
\text { activities }+ \\
\text { conventional } \\
\text { PT (bobath } \\
\text { concept) }\end{array}$ & LOKOMAT & $\begin{array}{l}90 \mathrm{~min} / \text { day } \\
5 \text { times/week } \\
5 \text { weeks } \\
25 \text { sessions }\end{array}$ & $\begin{array}{l}\text { Gait speed } \\
6 \mathrm{MWT} \\
10 \mathrm{MWT}\end{array}$ & $\begin{array}{l}\text { FIM, SF36, } \\
\text { tinetti gait } \\
\text { scale }\end{array}$ & $\begin{array}{l}\text { Both groups } \\
\text { improved gait } \\
\text { performance but } \\
\text { experimental groups } \\
\text { produced } \\
\text { improvements that } \\
\text { are more functional }\end{array}$ \\
\hline $\begin{array}{l}\text { Ochi et al. } \\
{[19]}\end{array}$ & $\begin{array}{l}\text { Subacute } \\
\text { stroke }\end{array}$ & $\begin{array}{l}\text { Gait-assisted } \\
\text { robot-assisted } \\
\text { gait training } \\
\text { versus OGT }\end{array}$ & $\begin{array}{l}\text { Gait assisted } \\
\text { robot assisted } \\
\text { gait training + } \\
\text { CPT }\end{array}$ & $\begin{array}{l}\text { Over ground } \\
\text { CGT + CPT }\end{array}$ & $\begin{array}{l}\text { Gait } \\
\text { assistance } \\
\text { robot }\end{array}$ & $\begin{array}{l}80 \mathrm{~min} / \text { day } \\
5 \text { times/week } \\
4 \text { weeks }\end{array}$ & $\begin{array}{l}\text { Functional } \\
\text { ambulation } \\
\text { classification }\end{array}$ & $\begin{array}{l}\text { Muscle torque, } \\
\text { FIM, } 10 \text { MWT, } \\
\text { fugl-meyer (LE) }\end{array}$ & $\begin{array}{l}\text { Gait assisted robot } \\
\text { group has significant } \\
\text { improvements in gait } \\
\text { and peak torque than } \\
\text { over ground walking } \\
\text { on unaffected side }\end{array}$ \\
\hline $\begin{array}{l}\text { Morone et al. } \\
{[20]}\end{array}$ & $\begin{array}{l}\text { Subacute } \\
\text { stroke }\end{array}$ & $\begin{array}{l}\text { Robot-assisted } \\
\text { gait training } \\
\text { versus over } \\
\text { ground CGT }\end{array}$ & $\begin{array}{l}\text { Robot assisted } \\
\text { gait training + } \\
\text { CPT }\end{array}$ & $\begin{array}{l}\text { Over ground } \\
\text { conventional } \\
\text { gait training }+ \\
\text { CPT }\end{array}$ & $\begin{array}{l}\text { Gait trainer } \\
\text { robot }\end{array}$ & $\begin{array}{l}60 \mathrm{~min} / \text { day } \\
5 \text { times/week } \\
4 \text { weeks } \\
20 \text { sessions }\end{array}$ & $\begin{array}{l}\text { Functional } \\
\text { ambulation } \\
\text { category }\end{array}$ & $\begin{array}{l}\text { Rivermead } \\
\text { mobility index, } \\
6 \text { MWT, } \\
10 \text { MWT }\end{array}$ & $\begin{array}{l}\text { RAGT + CPT } \\
\text { groups had better } \\
\text { performance than } \\
\text { CGT + CPT on } \\
\text { outcome measures in } \\
\text { sub acute stroke } \\
\text { patients }\end{array}$ \\
\hline $\begin{array}{l}\text { Kelley et al. } \\
{[21]}\end{array}$ & $\begin{array}{l}\text { Chronic } \\
\text { stroke }\end{array}$ & $\begin{array}{l}\text { Over ground } \\
\text { versus robotic- } \\
\text { assisted LT }\end{array}$ & $\begin{array}{l}\text { LOKMAT Gr } \\
\text { Pre }(n=11)\end{array}$ & $\begin{array}{l}\text { Over ground } \\
\text { gait training } \\
\text { group }\end{array}$ & LOKOMAT & $\begin{array}{l}1 \mathrm{~h} / \text { day } \\
5 \text { times/week } \\
8 \text { weeks } \\
40 \text { sessions }\end{array}$ & $\begin{array}{l}6 \mathrm{MWT}, \\
10 \mathrm{MWT}\end{array}$ & $\begin{array}{l}\text { FIM locomotion } \\
\text { part, FM-LE, } \\
\text { barthel index, } \\
\text { stroke impact } \\
\text { scale }\end{array}$ & $\begin{array}{l}\text { Both groups } \\
\text { improved no } \\
\text { significant } \\
\text { differences B/W } \\
\text { the groups }\end{array}$ \\
\hline $\begin{array}{l}\text { Bang and Shin } \\
{[22]}\end{array}$ & $\begin{array}{l}\text { Chronic } \\
\text { stroke }\end{array}$ & $\begin{array}{l}\text { LOKOMAT } \\
\text { versus TGT }\end{array}$ & LOKOMAT & TAGT & LOCOMAT & $\begin{array}{l}1 \mathrm{~h} / \text { day } \\
5 \text { times/week } \\
4 \text { weeks } \\
20 \text { sessions }\end{array}$ & $\begin{array}{l}\text { Gait speed, } \\
\text { cadence, } \\
\text { step length }\end{array}$ & $\begin{array}{l}\text { BBS, activity } \\
\text { specific balance } \\
\text { confidence }\end{array}$ & $\begin{array}{l}\text { LOKOMAT training } \\
\text { is better than TGT in } \\
\text { all the outcome } \\
\text { measures }\end{array}$ \\
\hline
\end{tabular}

RAGT, robotic-assisted gait training; TAGT, therapist-assisted gait training; CGT, conventional gait training; CPT, conventional physical therapy; 6 MWT, 6 min walk test; mEFAP, modified emory functional ambulation profile; SF-36, short form 36; BBS, Berg Balance Scale; FAI, Frenchay Activities Index; SPPB, short physical performance battery; LLFDI, late life function and disability instrument; FIM, Functional Independence Measure; 10 MWT, 10 m walking test; MAS, Motor Assessment scale; TGT, treadmill gait training; LT, locomotor training. 


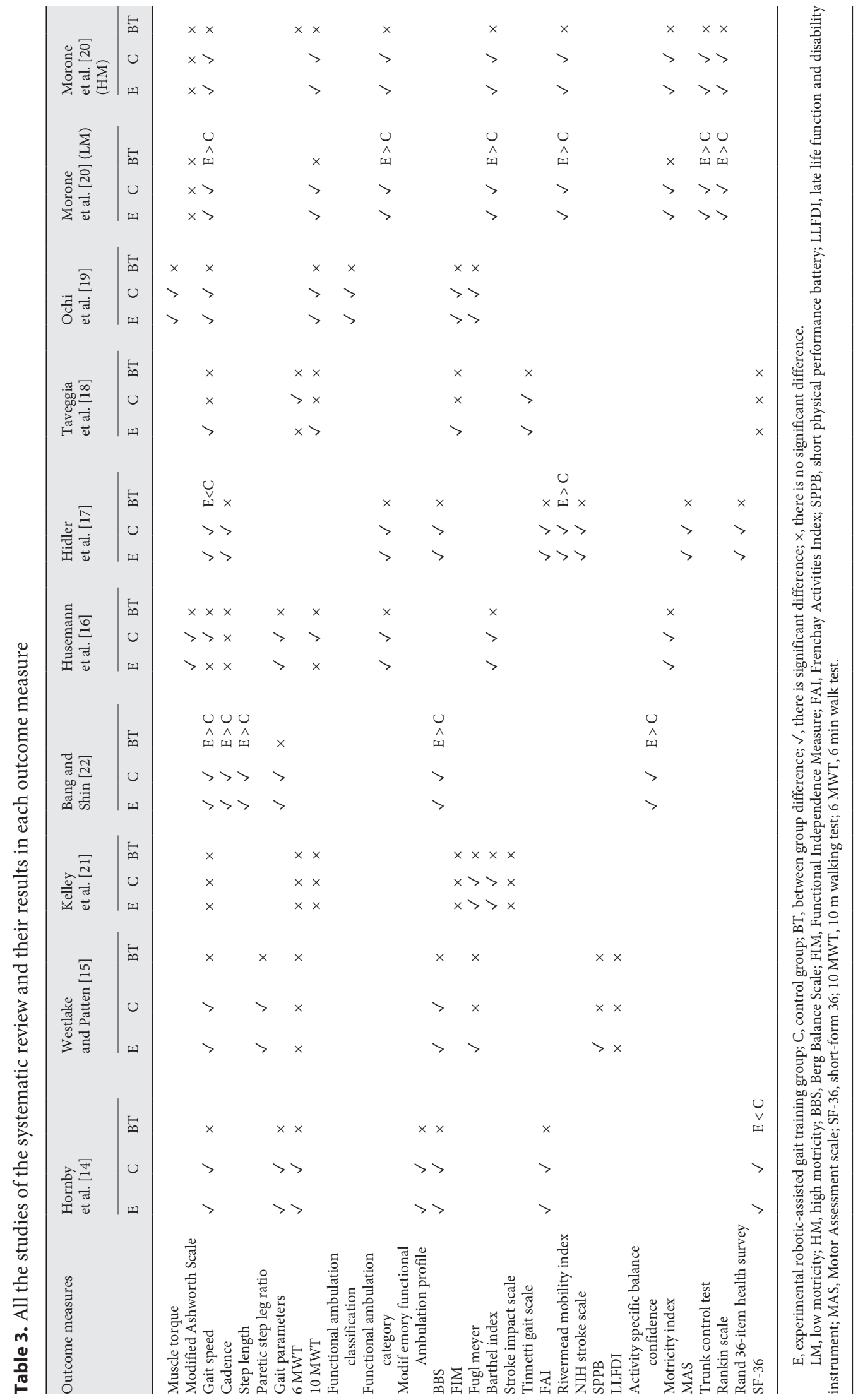


Table 4. Effect size values of robotic training on gait speed from various RCTs with 95\% CI

\begin{tabular}{|c|c|c|c|c|c|}
\hline Hornby et al. [14] & Chronic & 48 & -0.09 & -0.36 & 0.20 \\
\hline Westlake and Patten [15] & Chronic & 16 & 0.11 & -0.41 & 0.57 \\
\hline Husemann et al. [16] & Sub-acute & 30 & -0.35 & -0.63 & 0.02 \\
\hline Hidler et al. [17] & Sub-acute & 63 & -0.91 & -0.94 & -0.85 \\
\hline Taveggia et al. [18] & Sub-acute & 28 & 0.16 & -0.23 & 0.50 \\
\hline Morone et al. [20] (HM) & Sub-acute & 24 & -0.11 & -0.49 & 0.31 \\
\hline Kelley et al. [21] & Chronic & 21 & -0.29 & -0.64 & 0.16 \\
\hline Bang and Shin [22] & Chronic & 18 & 0.64 & 0.24 & 0.85 \\
\hline Sub-acute total & Sub-acute & 195 & -0.48 & -0.58 & -0.35 \\
\hline Chronic total & Chronic & 103 & 0.04 & -0.17 & 0.24 \\
\hline Grand total & All cases & 298 & -0.12 & -0.24 & 0.00 \\
\hline
\end{tabular}

LM, low motricity; HM, high motricity; RCTs, randomized controlled trials.

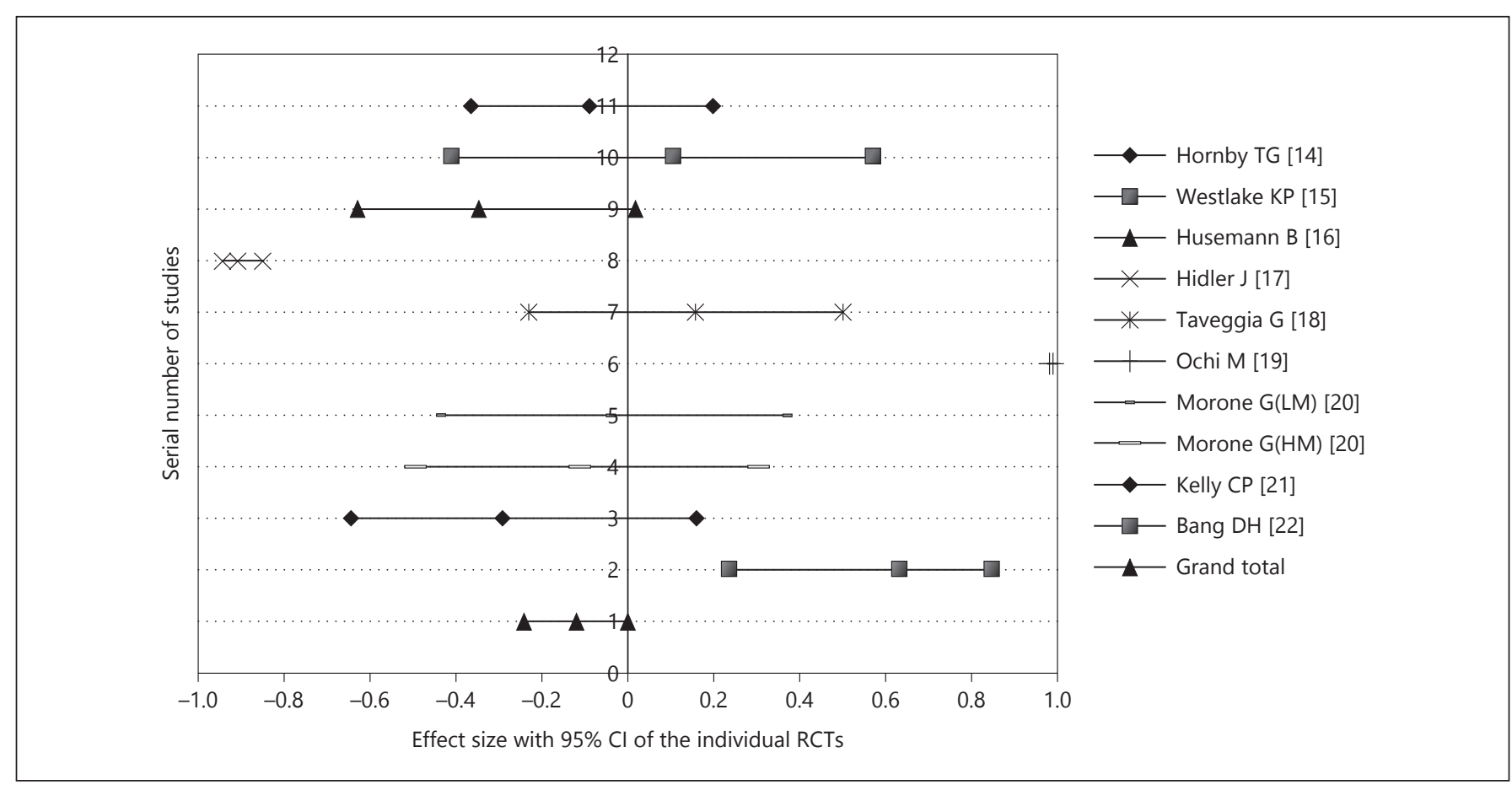

Fig. 2. Meta-analysis of gait speed in RCTs of subacute and chronic stroke population. RCTs, randomized controlled trials.

aerobic metabolism and improve cardiovascular training $[16,23,24]$, increase muscle mass and decrease fat mass, and reduce the complications of immobilization. Furthermore, it is cost-effective in the long run [16] and induces optimal joint kinematics during gait [22]. These improvements are possible with RAGT because of body weight adjustments, speed control, and increasing or de- creasing guidance forces applied on the affected side $[22$, $25-28]$.

In the stroke population, common impairments such as poor balance, weakness, malalignment, joint instability, and abnormal tone can decrease movement efficiency and act as a hurdle for functional improvement $[17,22,26]$. RAGT may aid stroke survivors with overcoming such 
problems by allowing them to practice typical gait patterns, temporarily reduce their body weight to achieve normal alignment, assist with foot clearance, and promotes an automated intensive walking training program [27].

Even though RAGT is an excellent mode of facilitating gait training, some of the researchers did note certain disadvantages such as skin integrity problems due to the excessive abnormal forces applied by straps attached to the paretic limb and fatigue due to excessive intensity and duration [21]. Some earlier robot designs also restricted participants' trunk and pelvic movements, adversely affecting pelvic movement during gait training [17]. This might be one of the reasons for the nonimprovements of gait observed in some of the studies.

Of note, in one study, the researchers surmised that over-ground training facilitates gait capacity better than RAGT [14]. The researchers hypothesized that these improvements were due to the maximal volitional drive of muscle activity and increased metabolic activity, which may in turn lead to better adaptation.

Conversely, however, many authors have highlighted disadvantages of over-ground gait training such as excessive strain on the therapist $[15,20]$, the potential of fall, deep vein thrombosis [16], and hypotensive episodes [21]. Furthermore, as compared with RAGT, the training speed, duration, distances, gait symmetry, body alignment, and joint kinematics are poorer with over-ground gait training.

The improvements that occur in stroke survivors using RAGT can be impacted by the following reasons: type of the stroke; stage of the stroke; extent and severity of the lesion; type of machine used; selection of treatment parameters such as intensity, duration, frequency, and total number of sessions; psychological condition of the patient; and extent of previous training.

Recent prior systematic reviews on RAGT on stroke survivors $[4,5,29,30]$ have stated that RAGT is as effective as conventional training. However, RAGT is more advantageous than conventional training in terms of adjustable body weight support, early-stage gait training, and the potential for longer training sessions. In the current systematic review, we found similar findings in that RAGT is either better than or equivalent to conventional training. Per the meta-analysis, however, there was no statistically significant difference in the gait speed achieved with RAGT versus conventional gait training.

Future research should focus on the following strategies to improve the effectiveness of RAGT: reducing the body weight support as per the capability of subjects, increasing the walking duration and velocity, and reducing the guidance force on the affected leg [22, 25, 26, 31]. In- creasing the sample size, preserving the skin integrity, and designing an optimal patient-specific dosage plan are also some other important considerations.

Importantly, the current systematic review included only RAGT performed involving fixed-exoskeleton robots and compared such with conventional training alone. The only parameter that was chosen for meta-analysis was gait speed. Future systematic reviews should consider studies involving all types of robots for RAGT, and the comparison group should include a wide variety of options rather than just conventional training alone. Some authors have suggested that the advanced capabilities of newer robots like facilitating pelvic movements can overcome the disadvantages of older versions [17, 32]. Future systematic reviews should consider these aspects and try to conduct reviews involving sophisticated robotics technologies alone. The completion of meta-analyses involving other outcome measures such as function and quality of life is similarly encouraged so as to give a better justification for using robotics in stroke survivors.

\section{Conclusion}

The findings of the current systematic review emphasize the use of RAGT among stroke survivors, as RAGT has equal effects as conventional training in improving the functional capacity of stroke survivors. A meta-analysis of 9 studies revealed that there is no significant difference in the RAGT group versus the conventional training group regarding gait speed. However, a subanalysis of gait speed in chronic cases showed a trivial positive revelation on effect size.

\section{Acknowledgment}

We thank Department of Medical Rehabilitation Sciences, College of Applied Medical Sciences, King Khalid University for the continuous encouragement and support.

\section{Statement of Ethics}

"The authors have no ethical conflicts to disclose."

\section{Disclosure Statement}

"The authors certify that there are no conflicts of interest with any financial organization regarding the material discussed in the manuscript." 


\section{Funding Sources}

We sincerely thank the Deanship of Scientific Research, King Khalid University, Abha, Kingdom of Saudi Arabia for funding this research project - number R.G.P.1 /133/40.

\section{Author Contributions}

All the authors are involved and participated in designing of the study, data collection, data analysis, drafting, and final approval of the article.

\section{References}

1 Belas Dos Santos M, Barros de Oliveira C, Dos Santos A, Garabello Pires C, Dylewski V, Arida RM. A Comparative Study of Conventional Physiotherapy versus Robot-Assisted Gait Training Associated to Physiotherapy in Individuals with Ataxia after Stroke. Behav Neurol. 2018 Feb;2018:2892065.

2 Chen X, Zhou L, Zhang Y, Yi D, Liu L, Rao W, et al. Risk factors of stroke in Western and Asian countries: a systematic review and meta-analysis of prospective cohort studies. BMC Public Health. 2014 Jul;14(1):776.

3 Morone G, Paolucci S, Cherubini A, De Angelis D, Venturiero V, Coiro P, et al. Robot-assisted gait training for stroke patients: current state of the art and perspectives of robotics. Neuropsychiatr Dis Treat. 2017 May;13:1303-11.

4 Bruni MF, Melegari C, De Cola MC, Bramanti A, Bramanti P, Calabrò RS. What does best evidence tell us about robotic gait rehabilitation in stroke patients: A systematic review and meta-analysis. J Clin Neurosci. 2018 Feb;48:11-7.

5 Mehrholz J, Thomas S, Werner C, Kugler J, Pohl M, Elsner B. Electromechanical-assisted training for walking after stroke. Cochrane Database Syst Rev. 2017 May 10;5:CD006185.

6 Lynch EA, Hillier SL, Stiller K, Campanella RR, Fisher PH. Sensory retraining of the lower limb after acute stroke: a randomized controlled pilot trial. Arch Phys Med Rehabil. 2007 Sep;88(9):1101-7.

7 Wist S, Clivaz J, Sattelmayer M. Muscle strengthening for hemiparesis after stroke: A meta-analysis. Ann Phys Rehabil Med. 2016 Apr;59(2):114-24.

8 Zhang X, Yue Z, Wang J. Robotics in LowerLimb Rehabilitation after Stroke. Behav Neurol. 2017;2017:3731802.

9 Schmid A, Duncan PW, Studenski S, Lai SM, Richards L, Perera S, et al. Improvements in speed-based gait classifications are meaningful. Stroke. 2007 Jul;38(7):2096-100.

10 Patterson SL, Forrester LW, Rodgers MM, Ryan AS, Ivey FM, Sorkin JD, et al. Determinants of walking function after stroke: differences by deficit severity. Arch Phys Med Rehabil. 2007 Jan;88(1):115-9.

11 Dickstein R. Rehabilitation of gait speed after stroke: a critical review of intervention approaches. Neurorehabil Neural Repair. 2008 Nov-Dec;22(6):649-60.

12 Gordon NF, Gulanick M, Costa F, Fletcher G, Franklin BA, Roth EJ, et al.; American Heart Association Council on Clinical Cardiology, Subcommittee on Exercise, Cardiac Rehabilitation, and Prevention; the Council on Cardiovascular
Nursing; the Council on Nutrition, Physical Activity, and Metabolism; and the Stroke Council. Physical activity and exercise recommendations for stroke survivors: an American Heart Association scientific statement from the Council on Clinical Cardiology, Subcommittee on Exercise, Cardiac Rehabilitation, and Prevention; the Council on Cardiovascular Nursing; the Council on Nutrition, Physical Activity, and Metabolism; and the Stroke Council. Stroke. 2004 May;35(5):1230-40.

13 Snider L, Majnemer A, Darsaklis V. Feeding interventions for children with cerebral palsy: a review of the evidence. Phys Occup Ther Pediatr. $2011 \mathrm{Feb} ; 31(1): 58-77$.

14 Hornby TG, Campbell DD, Kahn JH, Demott T, Moore JL, Roth HR. Enhanced gait-related improvements after therapist- versus roboticassisted locomotor training in subjects with chronic stroke: a randomized controlled study. Stroke. 2008 Jun;39(6):1786-92.

15 Westlake KP, Patten C. Pilot study of Lokomat versus manual-assisted treadmill training for locomotor recovery post-stroke. J Neuroeng Rehabil. 2009 Jun;6(1):18.

16 Husemann B, Müller F, Krewer C, Heller S, Koenig E. Effects of locomotion training with assistance of a robot-driven gait orthosis in hemiparetic patients after stroke: a randomized controlled pilot study. Stroke. 2007 Feb; 38(2):349-54

17 Hidler J, Nichols D, Pelliccio M, Brady K, Campbell DD, Kahn JH, et al. Multicenter randomized clinical trial evaluating the effectiveness of the Lokomat in subacute stroke. Neurorehabil Neural Repair. 2009 Jan;23(1):5-13.

18 Taveggia G, Borboni A, Mulé C, Villafañe JH, Negrini S. Conflicting results of robot-assisted versususualgait training during postacuterehabilitation of stroke patients: a randomized clinicaltrial.IntJRehabilRes.2016Mar;39(1):29-35.

19 Ochi M, Wada F, Saeki S, Hachisuka K. Gait training in subacute non-ambulatory stroke patients using a full weight-bearing gait-assistance robot: A prospective, randomized, open, blinded-endpoint trial. J Neurol Sci. 2015; 353(1-2):130-6.

20 Morone G, Bragoni M, Iosa M, De Angelis D, Venturiero V, Coiro P, et al. Who may benefit from robotic-assisted gait training? A randomized clinical trial in patients with subacute stroke. Neurorehabil Neural Repair. 2011 Sep;25(7):636-44.

21 Kelley CP, Childress J, Boake C, Noser EA. Over-ground and robotic-assisted locomotor training in adults with chronic stroke: a blind- ed randomized clinical trial. Disabil Rehabil Assist Technol. 2013 Mar;8(2):161-8.

22 Bang DH, Shin WS. Effects of robot-assisted gait training on spatiotemporal gait parameters and balance in patients with chronic stroke: A randomized controlled pilot trial. NeuroRehabilitation. 2016 Apr;38(4):343-9.

23 Saunders DH, Sanderson M, Hayes S, Kilrane M, Greig CA, Brazzelli M, et al. Physical fitness training for stroke patients. Cochrane Database Syst Rev. 2016 Mar;3:CD003316.

24 Mackay-Lyons MJ, Makrides L. Longitudinal changes in exercise capacity after stroke. Arch Phys Med Rehabil. 2004 Oct;85(10):1608-12.

25 Banala SK, Kim SH, Agrawal SK, Scholz JP. Robot assisted gait training with active leg exoskeleton (ALEX). IEEE Trans Neural Syst Rehabil Eng. 2009 Feb;17(1):2-8.

26 Mayr A, Kofler M, Quirbach E, Matzak H, Fröhlich K, Saltuari L. Prospective, blinded, randomized crossover study of gait rehabilitation in stroke patients using the Lokomat gait orthosis. Neurorehabil Neural Repair. 2007 Jul-Aug;21(4):307-14.

27 Swinnen E, Duerinck S, Baeyens JP, Meeusen R, Kerckhofs E. Effectiveness of robot-assisted gait training in persons with spinal cord injury: a systematic review. J Rehabil Med. 2010 Jun;42(6):520-6.

28 Werner C, Von Frankenberg S, Treig T, Kon$\operatorname{rad} \mathrm{M}$, Hesse S. Treadmill training with partial body weight support and an electromechanical gait trainer for restoration of gait in subacute stroke patients: a randomized crossover study. Stroke. 2002 Dec;33(12):2895-901.

29 Cho JE, Yoo JS, Kim KE, Cho ST, Jang WS, Cho KH, et al. Systematic Review of Appropriate Robotic Intervention for Gait Function in Subacute Stroke Patients. Biomed Res Int. 2018 Feb 6;2018:4085298.

30 Lo K, Stephenson M, Lockwood C. Effectiveness of robotic assisted rehabilitation for mobility and functional ability in adult stroke patients: a systematic review. JBI Database Syst Rev Implement Reports. 2017 Dec;15(12): 3049-91.

31 Picelli A, Melotti C, Origano F, Neri R, Waldner A, Smania N. Robot-assisted gait training versus equal intensity treadmill training in patients with mild to moderate Parkinson's disease: a randomized controlled trial. Parkinsonism Relat Disord. 2013 Jun;19(6):605-10.

32 Riener R, Lünenburger L, Colombo G. Human-centered robotics applied to gait training and assessment. J Rehabil Res Dev. 2006 Aug-Sep;43(5):679-94. 